\title{
A Review of Medium Voltage Single-Core Cable Armouring, Induced Currents and Losses
}

\author{
Parya Zamani, Amir Foomezhi, Sobhan Ghorbani Nohooji \\ Eleccore Company, Ltd., South Melbourne, Australia \\ Email: pariya@eleccore.com, amir@eleccore.com,ghorbani@eleccore.com
}

How to cite this paper: Zamani, P., Foomezhi, A. and Nohooji, S.G. (2021) A Review of Medium Voltage Single-Core Cable Armouring, Induced Currents and Losses. Energy and Power Engineering, 13, 272-292. https://doi.org/10.4236/epe.2021.137019

Received: May 14, 2021

Accepted: July 19, 2021

Published: July 22, 2021

Copyright (อ 2021 by author(s) and Scientific Research Publishing Inc. This work is licensed under the Creative Commons Attribution International License (CC BY 4.0).

http://creativecommons.org/licenses/by/4.0/ (c) (i) Open Access

\begin{abstract}
Insulated underground cables have the potential to reduce power outages, maintenance costs, and transmission losses compared to overhead lines. On the other hand, they are exposed to several risks and physical damages, since they are buried in the ground. Though the cables are armoured in order to provide mechanical protection and achieve tensile strength, and also to provide effective conductance of earth fault currents. The main purpose of this paper is to introduce insulated underground cables, armouring process, and to analyze the induced currents in metallic parts such as sheath and armour that causeohmic losses which are categorized mainly in two groups as circulating current and eddy current. This paper presents a review on analytical techniques used to analyze the effect of magnetic fields, andcalculate the losses in the armour of the cables, besides providing the strategies and solutions used for armour loss reduction.
\end{abstract}

\section{Keywords}

Single-Core Cable, Armour, Armour Loss, Eddy Current, Circulating

Current, Hysteresis Losses

\section{Introduction}

As the reliability of power supply has become an increasingly significant factor, utilizing underground cables in distribution networks became an important issue to reduce the risk of major interruptions on overhead conductors due to storms. Insulated underground cables have the potential to reduce outages, maintenance costs, and transmission losses compared to overhead lines.

Medium voltage (MV) cables are widely used for power distribution between high voltage mains power supply and low voltage applications. The main purpose of choosing a cable is to safely provide adequate electrical power, with con- 
tinuous, trouble-free operation, in a system that can withstand unexpected demands and overload conditions.

A medium voltage insulated cable circuit consists of three single-core cables or one three-core cable with terminations at each end to connect to the transformer or switchgear within the network. The main differences between single-core and three-core cables are the thickness and approximate outer diameter of the cable, and the cable's weight which is less in single-core cable than the three-core type of the same section. Besides, in order to solve the problem of phase insulation, a single-core type is usually adopted. Although single-core cables are not quite suitable for multi-circuit line engineering of substation's inbound and outbound lines. When single-core cables connect to indoor distribution devices, due to the space limitations, they easily collide with one another, making the installation of cable terminals challenging [1].

The components of these cables that essentially determine the electrical and thermal behavior of the cable mainly consist of the current-carrying conductor, inner and outer semi-conductive layers as the insulation part, and the metallic screen. Conductors primarily made from stranded copper $(\mathrm{Cu})$ or Aluminum (Al). Even though copper has a long history as the material of choice for electrical products, the price developments led to an overall competition between copper and other potential alternative materials. The aluminum industry has therefore become the biggest threat of substitution for copper producers, compromising the monopoly position of copper as an electrically conductive material. In contrast to copper, abundant and low-cost deposits of aluminum were available with ore concentrations of $20 \%-40 \%$, while copper had already become scarce with ore concentrations of about $2 \%$. Concerning its quality as an electrical conductor, aluminum features conductivity values that are almost as qualified as those of copper, whereas aluminum is clearly superior as far as density is concerned [2]. Some of the advantages and disadvantages of aluminum are mentioned in Table 1.

Table 1. Advantages and disadvantages of aluminum compared to copper.

\begin{tabular}{ll}
\hline \multicolumn{1}{c}{ Advantages } & \multicolumn{1}{c}{ Disadvantages } \\
\hline $\begin{array}{l}\text { Aluminum has a more than three times smaller } \\
\text { specific weight compared to copper [3]. }\end{array}$ & $\begin{array}{l}\text { lower current carrying capacity (CCC) and } \\
\text { increased voltage drop, compared to a copper } \\
\text { cable of the same size }\end{array}$ \\
$\begin{array}{l}\text { The lighter weight of aluminum cable reduces the } \\
\text { tensile force placed on wire and poles. }\end{array}$ & $\begin{array}{l}\text { The larger diameter of aluminum strands with } \\
\text { a density of } 2703 \mathrm{~kg} / \mathrm{m}^{3} \text { at } 20^{\circ} \mathrm{C} \text { results in less } \\
\text { flexible cables than copper which is denser } \\
\left.\text { (8890 } \mathrm{kg} / \mathrm{m}^{3} \text { at } 20^{\circ} \mathrm{C}\right) \text { and is available in very }\end{array}$ \\
$\begin{array}{l}\text { The greater availability of raw aluminum. Global } \\
\text { bauxite as the world's main source of aluminum is } \\
\text { estimated at } 55 \text { - } 75 \text { billion tons, while world copper } \\
\text { resources are estimated at } 2.1 \text { billion tons [4]. }\end{array}$ & $\begin{array}{l}\text { expansion than copper that increases the risks } \\
\text { of sag and destructive forces in joints }\end{array}$
\end{tabular}


Generally, a conductor is insulated with polymers or polyethylene materials and there is also at least one semiconductive or screen layer. These cables are often designed with an insulating layer placed between two semiconductive layers in order to provide an equipotential surface to make the electric field of the insulating material uniform. The semiconductive layer forming the outer covering can be placed either by extruding the semiconductive composition on the conductor which is coated with at least the insulating layer, or by helically winding a tape of semiconductive composition on the same unit [5].

The rated voltage of a medium voltage cable is determined by the thickness of the whole insulation part around the conductor, which is set at specified levels according to standards.

The armour is an optional layer consists of metal wires or strips that are set over the separation sheath or bedding and provides additional protection where mechanical stress has the potential to cause damages to the cable. The armour wires usually earthed without running a separate earth conductor [6]. For multicore cables, steel wire armour is used (SWA), whereas a layer of protective aluminum armour (AWA) is used for single-core cables. This is because a magnetic field is produced by the current which induces an electric current (eddy currents) in any ferromagnetic armour material, such as steel, which could lead to the cable overheating. The non-magnetic aluminum armour prevents this from happening.

This paper presents the analysis of armoured cables, their pertinent characteristics, and provides information on the strengths and drawbacks, as well as calculation methods for armour losses.

The paper is organized as follows:

- Section 2 describes the armour of the cable, its characteristics, and the materials that can be used for this purpose.

- Section 3 focuses on the occurrence of the armour losses and describes the types of the losses.

- Section 4 reviews the different methods for calculating cable armour losses.

- Section 5 reports the conclusions of the work.

\section{Armour}

To protect cables from mechanical damages, cable armouring is employed [7]. Armour provides mechanical protection from crushing forces while serving as an Earth Continuity Conductor (ECC) to provide effective conductance of earth fault currents.

The external magnetic field of a three-core cable carrying balanced load currents quickly decreases to zero, because the vectorial sum of the spatial and time-resolved components of the field is zero. Thus, a useful degree of ferromagnetic armouring is achieved for three-core cables by the application of steel wire armour, which allows to contain the flux [8].

Nevertheless, the possibility of armouring single-core cables has been consi- 
dered from time to time with a wide variety of opinions as to the resulting loss values. The publication of promiscuous experimental data on armour losses, relating usually to the prohibitively great loss in low-tension cables of large current-carrying capacity, has recently directed the attention to minimize the losses, by careful design. As mentioned, if magnetic material is employed as armour for a three-core cable carrying a three-phase current, there is practically no trouble due to inductive effects, since the resultant magnetomotive force around the three cores is zero. In the case of single-core cables, however, the inductive effects may become so pronounced that armouring becomes impracticable. Thus, because of the very high losses that would occur in single-core cables with magnetic armour, nonmagnetic material has been used in recent years for armoured single-core cables in AC systems [9]. To reduce the losses in the cable armour using a different material for the armour, particularly using a non-ferromagnetic metal like copper, bronze, brass, or stainless steel, aluminum is possible [10]. Table 2 indicates the electrical properties of the common metals used in cables [11].

Taking price into consideration, copper wire armour (CWA) and aluminum wire armour (AWA) are the best choices for armouring single-core XLPE cables as they are non-magnetic, and hence there is no need to take the effects of eddy currents and hysteresis loss into account. Copper is far more resistant to corrosion than aluminum, but due to the higher cost of copper, aluminum is preferred. Aluminum is prone to corrosion, especially when buried in the ground or in other situations where moisture is present. If water penetrates the outer sheath of an AWA cable the armour will rapidly corrode and the earth fault capability of the cable will be reduced or lost entirely depending on the degree of corrosion. The protection of aluminum against corrosion is of particular importance, so, it is most important to utilize protection over exposed metal right up to and over the termination. The corrosion of aluminum usually takes the form of local pits which may quickly penetrate a sheath, although general surface attack may be quite small. The mechanism of pitting is associated with the local breakdown of the protective oxide film, in conditions that do not allow its repair, followed by cell action due to differential conditions of electrolyte concentrations or aeration. The presence of other underground services containing metals anodic to aluminum, such as lead, steel, or copper, may accelerate the attack. While some soils, such as in the made-up ground, are worse than others, it

Table 2. Electrical properties of metals.

\begin{tabular}{cccc}
\hline Metal & Relative conductivity & $\begin{array}{c}\text { Electrical resistivity at } \\
20^{\circ} \mathrm{C}\left(\Omega \cdot \mathrm{m}, 10^{-8}\right)\end{array}$ & $\begin{array}{c}\text { Temperature coefficient of } \\
\left.\text { resistance (per }{ }^{\circ} \mathrm{C}\right)\end{array}$ \\
\hline Copper & 100 & 1.724 & 0.0039 \\
Aluminum & 61 & 2.826 & 0.0040 \\
Steel & 12 & 13.80 & 0.0045 \\
\hline
\end{tabular}


is always essential to consider that any ground is aggressive and to ensure that good protection exists [12].

As mentioned, the induced electric current in ferromagnetic armour material may result in losses and temperature rise in the cable and become a cause of concern. The relevant information for these losses is provided in the next section.

\section{Armour Loss}

When a conductor cable carries alternating current, an alternating magnetic field is generated around it, which is much stronger if the conductor is surrounded by an iron-rich material, like steel wire as armour or steel conduit. The currents in a twin cable, or two single-core cables feeding a single load, will be the same. They will exert opposite magnetic effects which will almost cancel so that virtually no magnetic flux is produced if they are both enclosed in the same conduit or armouring as shown in Figure 1. The same is true of three-phase balanced or unbalanced circuits provided that all three are within the same steel armouring or steel conduit. Hence, all conductors of a circuit must be contained within the same cable, or are in the same conduit if they are single-core types.

If the single-core cable has a metal sheath that is non-magnetic, less magnetic flux will be produced. However, there will still be induced EMF in the sheath, which can give rise to a circulating current and sheath heating [13]. Circulating losses are due to currents flow in metallic sheaths circuits of single conductor power cables that are bonding at both ends and create a closed path. Eddy currents losses are due to induced currents in sheaths which circulate radially as a result of skin effect and azimuthally as a result of proximity effect. So, grounding system types including single-point bonding, both ends bonding, and cross bonding, play a major role in the losses incurred. The advantage of single-point grounding systems is lower losses and its disadvantage is creating induced voltage at the unearthed end of cables which can be high enough to be hazardous. Although it should be mentioned that in a faulty power cable system, currents should pass all lengths of cable to the ground which may cause additional losses

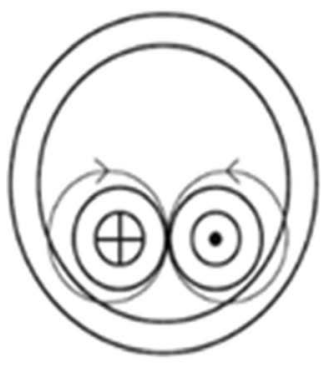

(a)

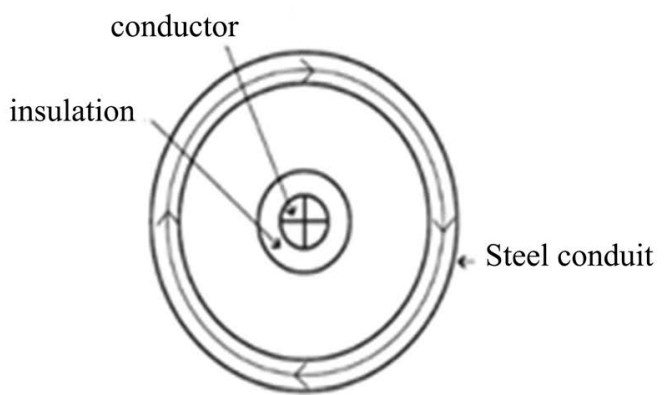

(b)

Figure 1. Iron losses in the steel surrounding a cable when it carries alternating current. (a) twin conductors of the same single-phase circuit, no losses; (b) single cone conductor high losses. (a) Near zero alternating flux; (b) strong alternating flux. 
[14]. While in both ends bonding systems, there is no induced voltage at the ends of cables. In the failure situation of such systems, currents are divided into two portions that cause reduction of fault losses. But these systems have additional losses at steady-state conditions due to circulating currents in metallic sheaths. The cross-bonding method decreases circulating currents and high induced voltage as well. In this method, the cable system is consisting of three sections with repeating all three-phase sheaths in each part. In an ideal case, induced voltages in sheaths are equal in magnitude with $120^{\circ}$ phase difference. Thus, the total voltage in each part is equal to zero. This method can be used only in cable systems with long lengths. Also, its implementation is expensive and needs skilled workers to run. Therefore, the cross-bonding method is not capable to perform in any situation.

It should be mentioned that eddy currents of sheaths occur in both multi-conductor and single conductor cables and also in single point or two ends bonding systems. But in the case of bonding sheaths at two ends these currents are small compared to circulating currents. Thus, eddy current losses can be ignored in cable analysis on both ends of grounding systems [15]. These losses are related to the magnetic field generated by AC current transported by the electric conductors, which causes eddy currents in the layers surrounding the cores (like, for example, the metal screen and the wires of the armour) and magnetic hysteresis of the ferromagnetic wires of the armour [16].

At present, IEC 60287 is used to calculate the sheath and armour losses for single-core cables with nonmagnetic armour [17], though this paper presents methods by different authors for calculating sheath and armour losses, in the next section.

\section{Calculation of Armour Loss}

Losses in protective armouring fall into several categories depending on the cable type, the material of the armour, and installation methods.

When magnetic armour such as steel is used for single-core cable, losses due to eddy currents and hysteresis in the steel must be considered. A method of calculating these losses is given by Bosone [18], and results agree with those obtained in the limited experimental work reported by Whitehead and Hutchings [19]. The latter work demonstrated that the losses in the sheath and armour combination could be several times the conductor losses, depending on the bonding arrangements of the sheaths and armour. The armour losses are lowest when the armour and sheath are bonded and grounded together at both ends of a run. AC cable's armour wire has three types of losses. Firstly, the Joule losses due to the armour's resistance and current flow in the longitudinal wire direction. This loss is well known as single-core cable loss and is caused when the single-core AC cable operates solidly bonded. Secondly, the eddy current loss is caused by induced currents by the magnetic flux in the armour wire formed by the conductor current [20]. If the flux density $B_{y}$ is constant inside a wire with the diameter $d$, the eddy current loss $P_{a}$ in the wire is according to Equation (1) 
given in [20].

$$
P_{a}=\frac{\pi d^{4} \sigma \omega^{2} B_{y}^{2}}{64}
$$

where $d=$ the wire diameter, $\sigma=$ wire conductivity, $B_{y}=$ flux density, and $\omega=$ angular frequency.

The eddy current has its maximum value at the outer and inner parts of the wire. The equation gives the maximum power loss in an armoured single-core cable. Practically, the eddy current loss is lower than shown in Equation (1), since the skin effect will reduce the power loss inside the wire [21]. So, the eddy current varies due to the skin effects according to the properties of the ferromagnetic materials [20]. The magnitude of the magnetic flux density depends on the conductor current and the relative permeability $\mu_{e}$ of the magnetic steel material. The wires are supposed to have no metallic contact since the relative permeability will be decreased in the $\varphi$-direction through the armouring wires and the wire gaps. The wire gap $\delta$ reduces the total permeability $\mu_{t}$ according to Equation (2) from [20].

$$
\mu_{t}=\frac{d}{d+\mu_{e} \delta} \cdot \mu_{e}
$$

For magnetic steel materials, IEC 60287 recommends $\mu_{e}=400, \mu_{t}=10$ when wires are in contact, and $\mu_{t}=1$ where wires are separated.

$\mu_{t}=10$ determines the wire gap $\delta$ to be around $0.4 \mathrm{~mm}$ for $d=5 \mathrm{~mm}$. The permeability is then reduced about 40 times, compared to having the wires in direct metallic contact with each other. Instead of reducing the permeability of the magnetic steel material itself, the magnetic field intensity $H$ is then reduced indirectly by the existing wire gaps in the cable. For example, a magnetic field intensity $H=4000 \mathrm{~A} / \mathrm{m}$ originated from a conductor current $I=1500 \mathrm{~A}$, is reduced to about $100 \mathrm{~A} / \mathrm{m}$ (40 times) [21].

The third type of loss is hysteresis loss which is caused by the nonlinear characteristics of the ferromagnetic armour wires, that is relatively high for three-core combined cables, due to the low magnetic flux density in the armour [20].

For purposes of armouring single-core cables, there are special electrical requirements, such as low permeability and high resistivity which are difficult to obtain in conjunction with the mechanical requirements, and without raising the cost excessively.

In Figure 2 some oscillograph records of the sheath, armour, and core currents are given for $66 \mathrm{kV}$ cables with the lay of $68.2 \mathrm{~cm}$ [22].

It should be noted that on account of the variation of permeability of the armour, the induced voltages are not strictly proportional to the core currents. The effective permeability may be calculated from formula (3) stated in [22].

$$
\mu=\left(\frac{10^{8} l}{0.4 \pi N^{2} A}\right) L
$$




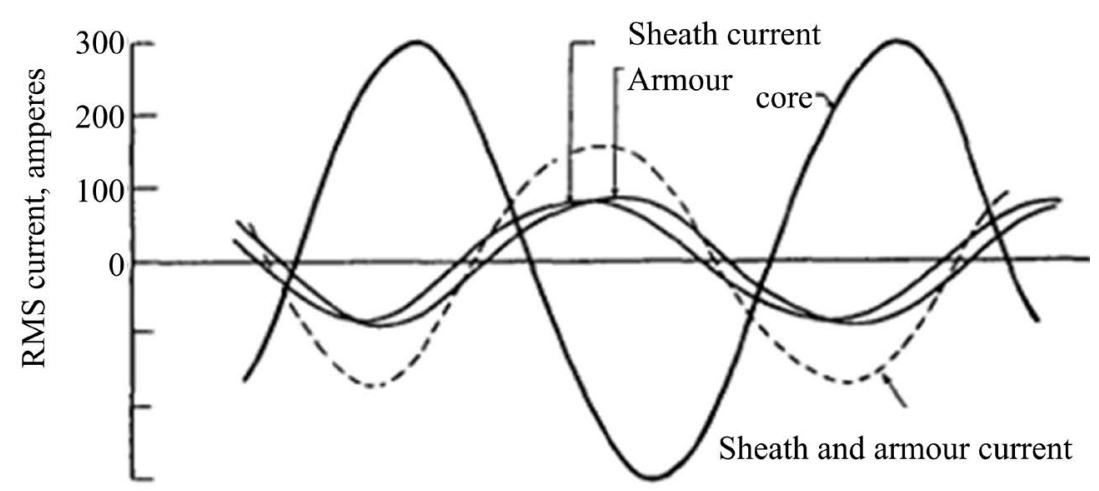

Figure 2. Oscillograph records of sheath and armour current when bonded.

where $l$ is the length of the sample $(\mathrm{cm}), N$ is the number of turns on the magnetizing coil, $A$ is the area of cross-section of iron of armour wire $\left(\mathrm{cm}^{2}\right)$, and $L$ is the inductance of coil.

Tests taken on several samples of ordinary galvanized iron wires are given in Figure 3 and Figure 4. A key to the numbering of the curves is given in Table 3.

The curve so obtained is shown in Figure 5 and will be seen to be almost identical with those obtained from the tests on the wire samples 1 and 2 (Figure 4 ), except for small values of $\mathrm{H}$, in which case the loss is rather higher in Figure 5 [22].

To minimize the losses in the case of single-core cables armoured with magnetic material the wire should be applied with as long a lay as possible. An effective increase in lay, and hence a reduction in armour loss, is obtained by intertwisting cables as indicated.

Based on the tests performed by Brockbank and Webb [22] by utilizing bridging method on single-core, lead-covered armoured $66 \mathrm{KV}$ cables, there is evidence that there are some ways to reduce armour loss when using magnetic materials for single-core cables. The external magnetizing force along the armour wires, causes a flux to alternate along the wires, which increases the losses due to eddy currents and hysteresis. The formula (4), stated in [22], shows that the only two variables are the core current and the length of wire per turn.

$$
H=0.4 \pi \frac{I}{l_{t}}
$$

In the above formula, $H$ is magnetizing force and $l_{t}$ is the length of one complete turn of armour as shown in Equation (5) from [22].

$$
l_{t}=\sqrt{\left(2 \pi r_{a}\right)^{2}+l^{2}}
$$

It is seen that by increasing the amount of $r_{a}$ and $l$ which are the mean radius through wires and the length of lay respectively, we can reduce the magnetized force. In the case of e.h.t. (Extra high tension) cables, the length of lay is larger than low-tension cables because of the greater diameter of the dielectric layer. It should be noted that the birdcage of the wire is a limit to the increment of lay length. 
Table 3. Wire samples referred to in Figure 3 and Figure 4.

\begin{tabular}{cc}
\hline Sample number & Diameter of wire (inch) \\
\hline 1 & 0.129 \\
2 & 0.127 \\
4 & 0.104 \\
5 & 0.083 \\
6 & 0.073 \\
\hline
\end{tabular}

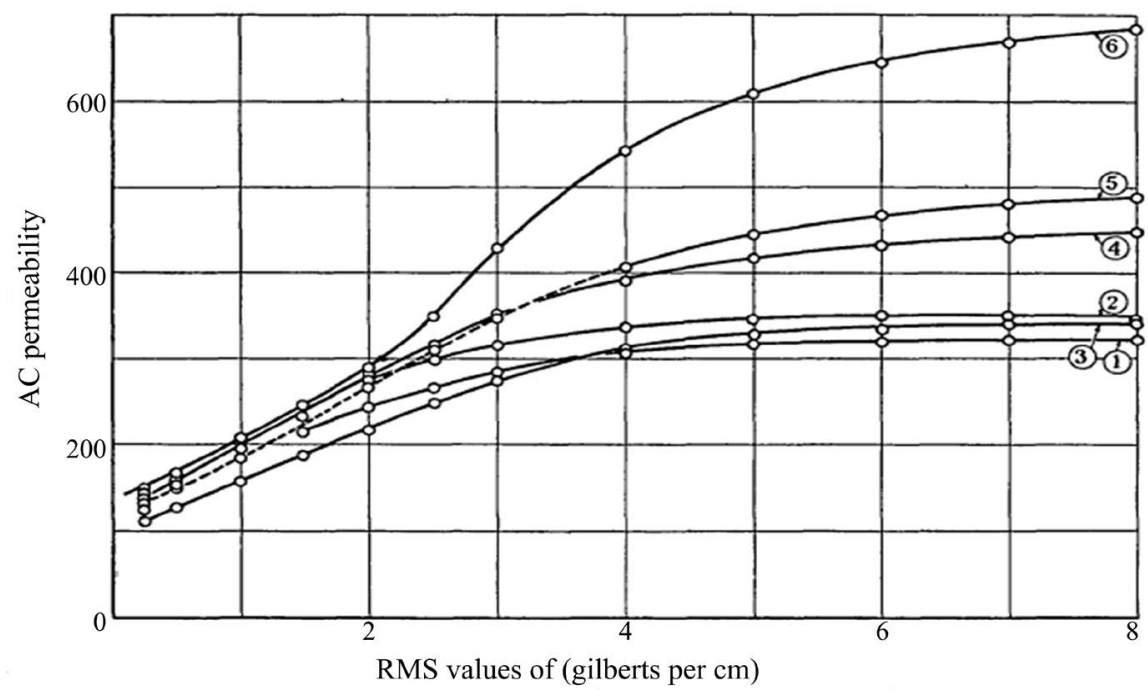

Figure 3. Magnetic tests on samples of armour wire at 50 cycles per sec.

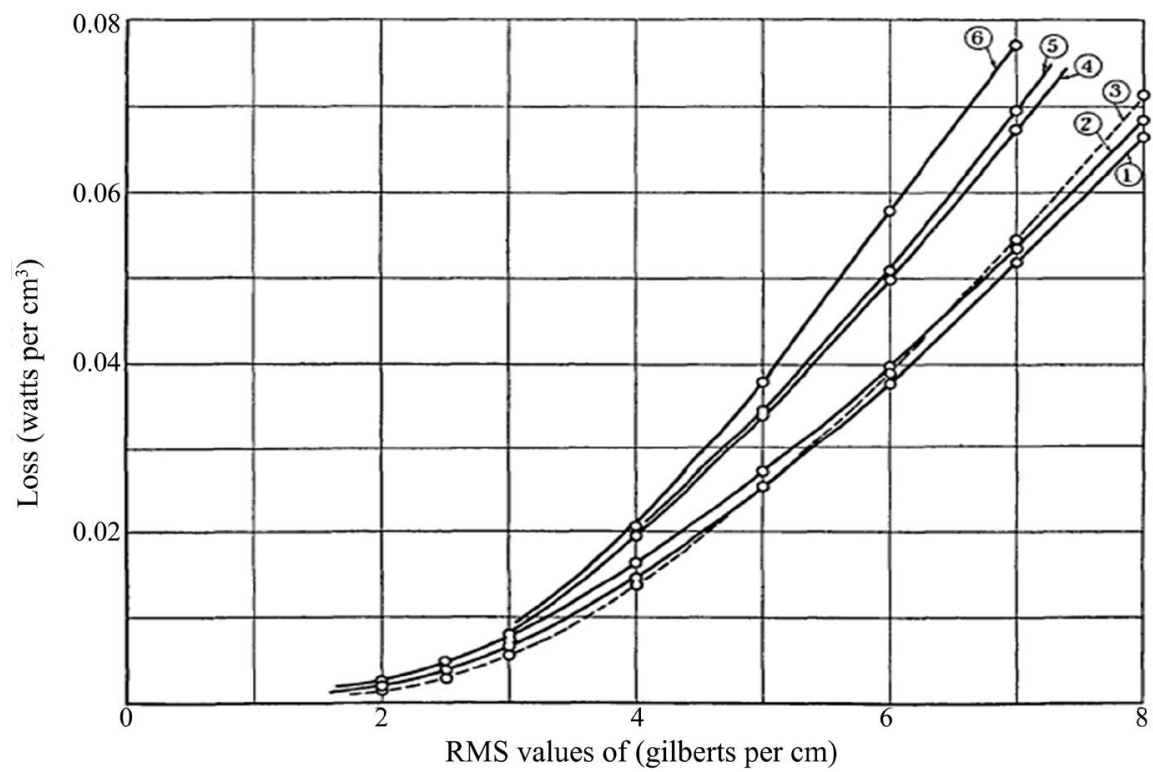

Figure 4. Magnetic tests on samples of armour wire at 50 cycles per sec.

Intertwisting cables in the same sense as the armour, as showed in Figure 6, can help to increase the effective lay. 


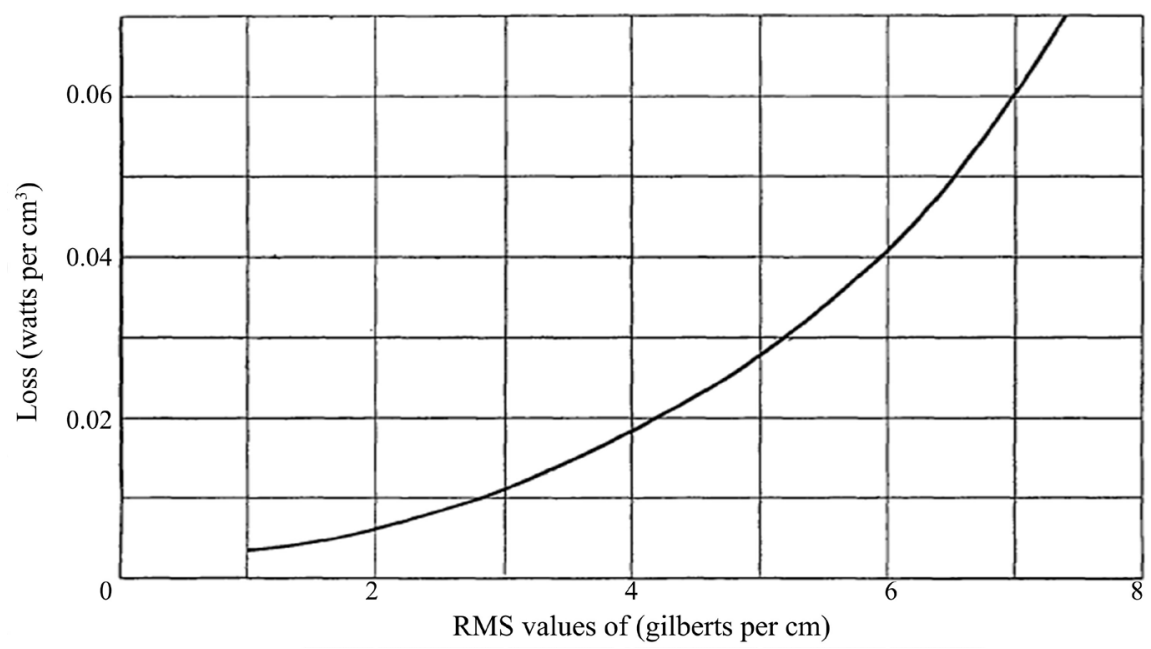

Figure 5. Variation of loss with magnetizing force in 0.128-inch armour wire. Deduced tests on armoured cables.

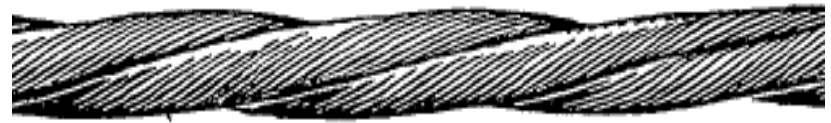

Figure 6. The three cables of a 3-phase system intertwisted.

Therefore $H^{\prime}$ as magnetizing force along wires due to current in adjacent cables is equivalent to Equation (6) from [22].

$$
H^{\prime}=0.4 \pi \frac{I}{l_{t}^{\prime}}
$$

where $l$ ' is the length of armour wire encircled by one turn of adjacent cable (or cables) forming return path. Accordingly, the resultant magnetizing force acting along the wires is shown in Equation (7) given in [22]:

$$
H+H^{\prime}=\frac{0.4 \pi I}{l_{t} l_{t}^{\prime} /\left(l_{t}^{\prime}-l_{t}\right)}
$$

The tests were performed by using the bridge method to measure the ratio of the AC to the DC loss on six groups of cables designed with 46/0.128-inch galvanized steel armour wire, with different lays as Table 4 . The lays were measured by counting the number of complete twists of wire in a given length. For groups $\mathrm{D}, \mathrm{E}$, and $\mathrm{F}$ the cables were twisted together in the same sense as the armour wire. Throughout the tests, measurements were in general made at five different values of the current ranging from 50 to 300 amperes.

The tests on single-phase resulted in the curves in Figure 7 and Figure 8, which shows the relationship between the loss per $\mathrm{cm}^{3}$ and the root-mean-square value of $H$ along the wire when lead and armour are bonded and cables are in contact. As can be seen in Figure 7, increasing the effective lay by twisting the cables reduces the losses [22].

From Harvey and Busby [23] experiment it has been shown that watt loss on a 
Table 4. Group of cables designed with 46/0.128-inch galvanized steel armour wire, with different lays.

\begin{tabular}{cccc}
\hline Group & $\begin{array}{c}\text { Lay of wire on cable } \\
(\mathrm{cm}), l\end{array}$ & $\begin{array}{c}\text { Lay of twist of two } \\
\text { cables }(\mathrm{cm}), l^{\prime}\end{array}$ & $\begin{array}{c}\text { Effective lay }(\mathrm{cm}), \\
l l^{\prime} /\left(l^{\prime}-l\right)\end{array}$ \\
\hline A & 54 & - & - \\
B & 86.2 & - & - \\
C & 130.3 & - & - \\
D & 71 & 250 & 99 \\
E & 71 & 125 & 164.3 \\
F & 130.3 & 200 & \\
\hline
\end{tabular}

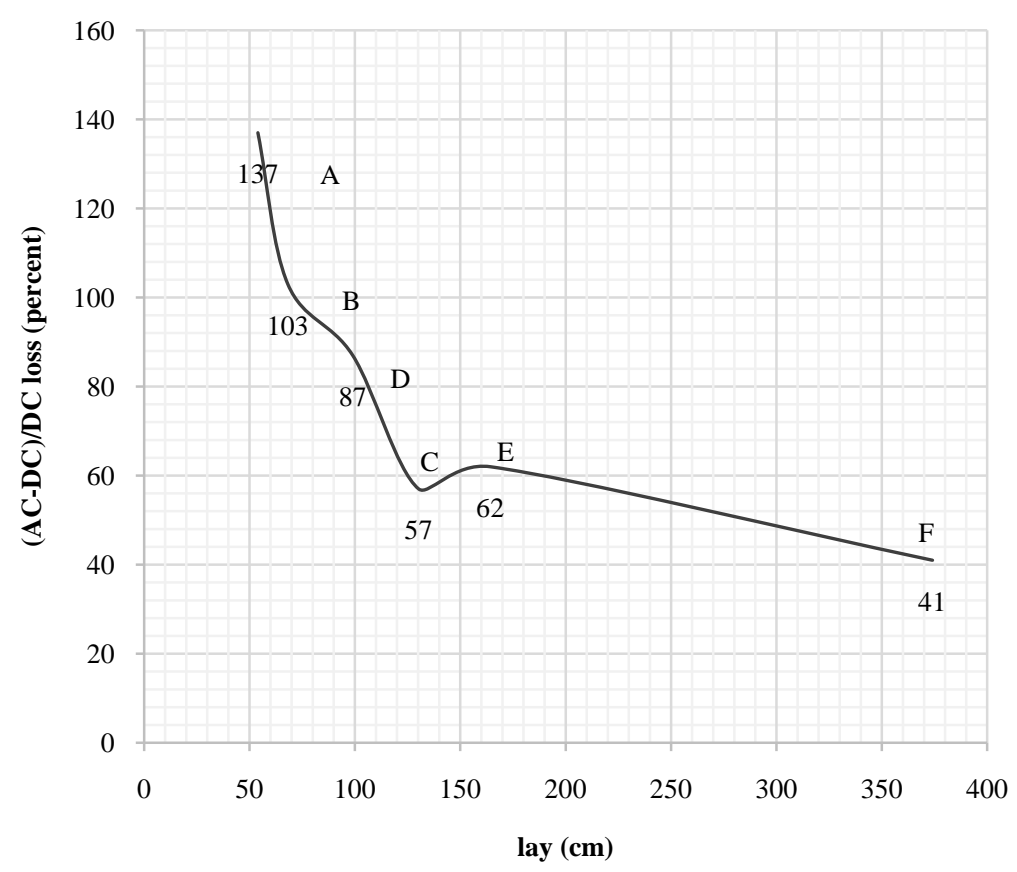

Figure 7. The variation of loss with the lay of $0.128 \mathrm{in}$. armour wire on $66 \mathrm{kV}$ cable with $I$ $=300$ amps.

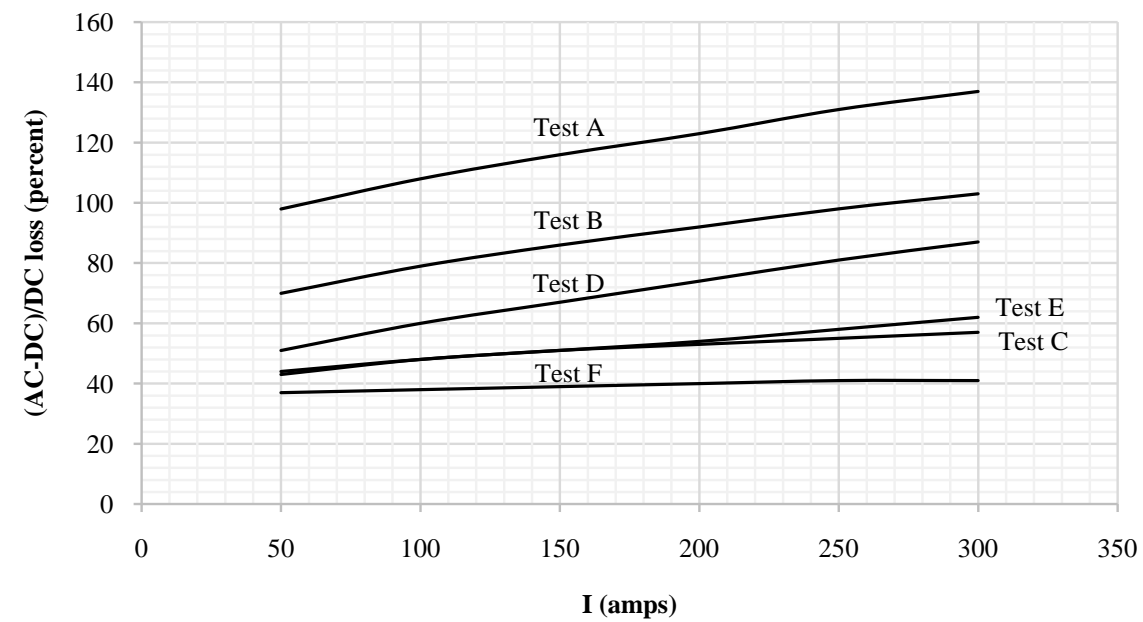

Figure 8. The variation of loss with the lay of $0.128 \mathrm{in}$. armour wire on $66 \mathrm{kV}$ cable for different tests. 
500-volt circuit for the single-armoured cables [tests (E) and (G)] is 2.16 percent of the power input for every 100 yards of the circuit, and for the double-armoured cable [test (F)] 4.27 percent. In Figure 9 the watts lost per ampere of the main current per 100 yards of the circuit are plotted, for each of the tests, against the main current as a percentage of the I.E.E. rating.

From the tests results as shown in Table 5, it has been determined that by decreasing the permeability and sectional area of the magnetic armour wire, the losses will be reduced [23].

However, in Cramp's review of the Harvey and Busby test G, it is shown that the flux density in the armour is far greater than that based upon the circumferential flux as given by Harvey and Busby.

Each armoured wire is a permeable conductive cylinder that is magnetized by an external force called $H$, which is parallel to the length of the wire, as shown in Equation (8) from [24]:

$$
H=0.2 \sqrt{(2) I \cos \theta \sin 2 \pi f t / r}
$$

To calculate Eddy loss by means of the Kelvin functions ber $=\left[r_{1} \sqrt{(\mu f)} / \rho\right]$ and $b e i=\left[r_{1} \sqrt{(\mu f)} / \rho\right]$ for test $\mathrm{G}$ with $\mu=500$ :

ber $=\left[r_{1} \sqrt{(\mu f)} / \rho\right]=0.8$ and $b e i=\left[r_{1} \sqrt{(\mu f)} / \rho\right]=0.8$ approximately, the corresponding differential coefficients being 0.4 and 0.8 respectively.

Then the eddy losses per $\mathrm{cm}^{3}$ of iron are 0.0046 watts at 100 percent of I.E.E. rating for the current in the core, corresponding to 0.0076 watts per $\mathrm{cm}$ length of cable.

Similarly, we can arrive at an approximate value for the hysteresis loss.

If we assume that:

$$
\begin{array}{r}
r_{1} \sqrt{(\mu f)} / \rho=x \\
r^{\prime} \sqrt{(\mu f)} / \rho=x^{\prime}
\end{array}
$$

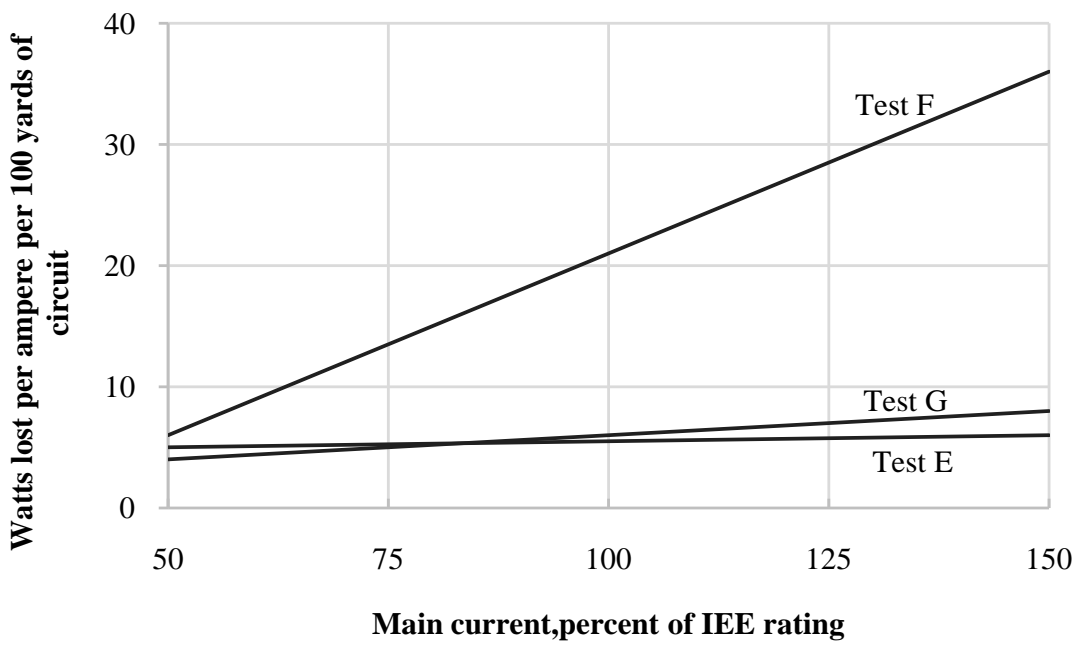

Figure 9. The watts lost per ampere of the main current per 100 yards of the circuit are for the tests E, F, G, against the main current as a percentage of the I.E.E. rating. 
Table 5. Comparative table of results.

\begin{tabular}{|c|c|c|c|}
\hline Test & Test (E) & Test (F) & Test (G) \\
\hline Size of the main cable & $37 / 0.092$ in. & $37 / 0.092$ in. & $19 / 0.072$ in. \\
\hline IEE rating (amperes) & 214 & 214 & 97 \\
\hline Type of the sheath & Armour & Armour & Armour \\
\hline Description of the sheath & Single & Double & Single \\
\hline External diameter of the sheath & 1.55 in. & $1.77 \mathrm{in.}$ & 1.16 in. \\
\hline Resistance of sheath per 100 yards of circuit, ohms & 0.122 & 0.056 & 0.124 \\
\hline Permeability of sheath section & 6 & 17 & 11 \\
\hline Sheath current for IEEE rating (main current), amps & 0.5 & 0.46 & 0.33 \\
\hline Ratio: Sheath current/main current & 0.0023 & 0.0021 & 0.0034 \\
\hline $\begin{array}{l}\text { Percentage increase in sheath current for } d=12 \text { in } \\
\text { over that for } d=0\end{array}$ & 21.4 & 10.5 & 28.8 \\
\hline $\begin{array}{l}\text { Percentage increase in sheath current for } d=48 \text { in } \\
\text { over that for } d=0\end{array}$ & 40 & 11.1 & 52 \\
\hline Impedance per 100 yards of circuit, ohms & 0.125 & 0.157 & 0.177 \\
\hline Dead resistance per 100 yards of circuit, ohms & 0.029 & 0.035 & 0.065 \\
\hline Effective resistance per 100 yards of circuit, ohms & 0.0505 & 0.093 & 0.109 \\
\hline Ration: Impedance/Dead resistance & 4.3 & 4.5 & 2.73 \\
\hline Ration: Effective resistance/Dead resistance & 1.74 & 2.68 & 1.68 \\
\hline $\begin{array}{l}\text { Watts loss per ampere of the main current per } 100 \\
\text { yards of circuit }\end{array}$ & 10.8 & 21.3 & 10.9 \\
\hline Voltage drop per 100 yards of circuit, volts & 26.6 & 42.3 & 17.7 \\
\hline
\end{tabular}

where $r^{2}$ is the radial distance measured from the center of the iron wire, the magnetic density in the wire at radius $r$ ' will be calculated from Equation (11) from [24]:

$$
B=\frac{0.2 \sqrt{(2) \mu I \cos \theta}}{r} \times \frac{\sqrt{\left[\operatorname{ber}^{2}\left(x^{\prime}\right)+b e i^{2}\left(x^{\prime}\right)\right]}}{\sqrt{\left[\operatorname{ber}^{2}(x)+b e i^{2}(x)\right]}}
$$

from which the distribution of flux over the area of one wire, as seen in Figure 10 , may be calculated.

To calculate hysteresis loss using the Steinmetz index with the coefficient of 0.003, 0.0064 watts dissipated in hysteresis per $\mathrm{cm}$ length of cable at 100 percent of I.E.E. rating for the current in the core. Adding these to the eddy losses already calculated, we obtain $0.0076+0.0064=0.014$ watts in iron loss per $\mathrm{cm}$ of cable.

It is also showed that due to the larger ratio of diameter over armour to conductor's diameter, and thicker insulation layer in h.t cables, the eddy currents and hysteresis losses are smaller than l.t cables [24].

The comparison of the tests with $\mu=500$ and hysteresis coefficient $h=0.03$ are shown in Table 6. 


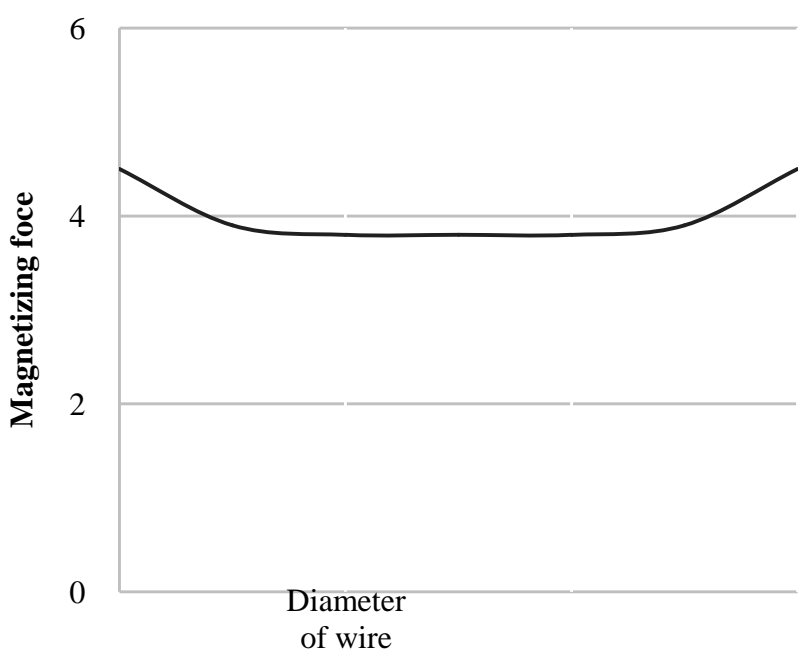

Figure 10. Variation of magnetizing force with the diameter of armour wire.

Table 6. Losses per cm length of cable [24].

\begin{tabular}{cccc}
\hline & l.t cable & \multicolumn{2}{c}{ h.t cable } \\
\cline { 2 - 4 } Cable size & 0.5 sq. in. & $\begin{array}{c}0.1 \text { sq. in. } \\
(22,000 \text { volts })\end{array}$ & $\begin{array}{c}0.1 \text { sq. in. } \\
(132,000 \text { volts })\end{array}$ \\
\hline I.E.E rating & 540 amperes & 191 amperes & 191 amperes \\
Armour wire thickness & $=$ ht22000 & $=l$ & 0.104 in. \\
Core loss (copper loss) & 0.16 watt & 0.1 watt & 0.01 watt \\
Eddy loss in the armour & 0.17 watt & 0.021 watt & 0.008 watt \\
Hysteresis loss in the armour & 0.08 watt & 0.016 watt & 0.009 watt \\
Total armour loss & 0.25 watt & 0.037 watt & 0.017 watt \\
Ratio (armour loss)/(copper loss), percent & $1 \%$ & $37 \%$ & $17 \%$ \\
\hline
\end{tabular}

In [25] to obtain sheath and armour loss factors, the total inductance between elements is calculated by the sum of internal and external inductances. For magnetic permeability of free space as $\mu_{0}\left(4 \pi \times 10^{-7} \mathrm{H} / \mathrm{m}\right)$, the outer radius of the conductor $r_{\odot}$ the axial distance between conductors $\mathrm{S}$, effective conductor radius $\mathrm{ar}_{c}$, mean radius of the armour $r_{a}$, is the armour thickness $t_{a}$, complex relative longitudinal magnetic permeability $\mu_{\mathrm{e}}$ complex relative transverse magnetic permeability $\mu_{b}$ helical lay length of the armour $l_{a}$, helical lay angle with respect to the cable axis $\beta$, and $A_{a}$ as the sum of the wire or tape cross-sectional areas, the total conductor-conductor inductance $L_{c c}$ is given by Equation (12) given in [25]:

$$
L_{c c}=\frac{\mu_{0}}{2 \pi} \ln \left(\frac{s}{\alpha r_{c}}\right)+\frac{\mu_{0}}{2 \pi} \frac{t_{a}}{r_{a}}\left[\mu_{t} \cos ^{2}(\beta)-1\right]+\frac{\mu_{0} \mu_{e} A_{a}}{2 \pi r_{a} l_{a}} \sin \beta
$$

Also, total conductor-sheath inductance $L_{c s}$, total sheath-sheath inductance $L_{s s}$ total conductor-armour and sheath-armour inductance $L_{c a}$ and $L_{s a}$ and the armour-armour inductance $L_{a a}$ is are given by (13), (14), (15) and (16) from [25]: 


$$
\begin{gathered}
L_{c s}=\frac{\mu_{0}}{2 \pi} \ln \left(\frac{s}{r_{s}}\right)+\frac{\mu_{0}}{2 \pi} \frac{t_{a}}{r_{a}}\left[\mu_{t} \cos ^{2}(\beta)-1\right]+\frac{\mu_{0} \mu_{e} A_{a}}{2 \pi r_{a} l_{a}} \sin \beta \\
L_{s s}=\frac{\mu_{0}}{2 \pi} \ln \left(\frac{s}{r_{s}+t_{s} / 6}\right)+\frac{\mu_{0}}{2 \pi} \frac{t_{a}}{r_{a}}\left[\mu_{t} \cos ^{2}(\beta)-1\right]+\frac{\mu_{0} \mu_{e} A_{a}}{2 \pi r_{a} l_{a}} \sin \beta \\
L_{c a}=L_{s a}=\frac{\mu_{0}}{2 \pi} \ln \left(\frac{s}{r_{a}+t_{a} / 2}\right)+\frac{\mu_{0} \mu_{t}}{2 \pi} \frac{t_{a}}{r_{a}}\left[\frac{1}{2}-\sin ^{2}(\beta)\right]+\frac{\mu_{0} \mu_{e} A_{a}}{2 \pi r_{a} l_{a}} \sin \beta \\
L_{a a}=\frac{\mu_{0}}{2 \pi} \ln \left(\frac{s}{r_{a}+t_{a} / 2}\right)+\frac{\mu_{0} \mu_{t}}{2 \pi} \frac{t_{a}}{r_{a}}\left[\frac{1}{3 \cos ^{2}(\beta)}-\sin ^{2}(\beta)\right]+\frac{\mu_{0} \mu_{e} A_{a}}{2 \pi r_{a} l_{a}} \sin \beta
\end{gathered}
$$

For nonmagnetic armour the last two terms in Equation (13) and (14) are ignored and in Equation (15) the second term becomes $\mu_{0} t_{a} / 4 \pi r_{a}$ and the last term is ignored.

Additionally, for Equation (16) the second term becomes $\mu_{0} t_{a} / 6 \pi r_{a}$ and the last term is ignored with the presence of nonmagnetic armour.

As it can be seen in [25] by the use of nonmagnetic armour the inductances between elements can be reduced, thus, in order to prevent high losses in closely spaced single-core cables with magnetic armour, later studies have been conducted on nonmagnetic materials as armour. For this purpose, IEC 60287 is used to calculate the combination of sheath and armour losses for single-core cables with nonmagnetic armour [17]. With using the parallel combination of sheath and armour resistance $R_{e}$, and the root mean square value of the sheath and armour diameter $d$, shown in Equation (17) and (18) respectively, sheath current and armour current can be expressed as in Equation (19) and (20) given in [26].

$$
\begin{aligned}
& R_{e}=\frac{R_{s} R_{a}}{R_{s}+R_{a}} \\
& d=\sqrt{\frac{d_{s}^{2}+d_{a}^{2}}{2}} \\
& I_{s}=\left(R_{e} / R_{s}\right) I_{s a} \\
& I_{a}=\left(R_{e} / R_{a}\right) I_{s a}
\end{aligned}
$$

where:

$R_{e}$ : The equivalent resistance of sheath and armour in parallel $(\mathrm{W} / \mathrm{m})$.

$R_{a}$ : The resistance of armour per unit length of cable at its maximum operating temperature $(\mathrm{W} / \mathrm{m})$.

$d$ : The mean diameter of sheath and armour $(\mathrm{mm})$.

$d_{s}$ : The mean diameter of the sheath $(\mathrm{mm})$.

$d_{a}$ : The mean diameter of the armour ( $\left.\mathrm{mm}\right)$.

$I_{s}$ : Sheath current (circulating or eddy) in A.

$I_{a}$ : Armour current (circulating or eddy) in A.

$I_{s a}$ Sheath-armour combination current in A.

Hence the total loss in the armour is calculated according to IEC 60287 as Equation (21) from [17]: 


$$
\lambda_{2}=\frac{\left(R_{s} R_{a}\right) / R_{s}+R_{a}}{R} \frac{1.5}{1+\left(\left(\frac{R_{s} R_{a}}{R_{s}+R_{a}}\right) / X\right)^{2}}
$$

where $R$ is the AC resistance of conductor $(\Omega / \mathrm{m})$ and $X$ is the reactance per unit length of cable $(\Omega / \mathrm{m})$ at their maximum operating temperature.

Armour currents and armour losses factors obtained from the investigation [26] for $800 \mathrm{~mm}^{2}$ single-core cable at $66 \mathrm{kV}$, that armoured with 50 aluminum wires with mean armour diameter $82.5 \mathrm{~mm}$, for touch trefoil and touch flat arrangement are given as Figure 11 and Figure 12 [26].

It can be seen that trefoil formation introduces symmetrical values of losses in its sheaths than flat formation addition to the total sheath losses in the trefoil are lower than flat layout [26].

In 2019 study of sheath and armour circulating current losses [27] for $11 \mathrm{kV}$, $400 \mathrm{~mm}^{2}$ single-core cables with aluminum alloy armour (XLPE/LC/AWA/PVC) carried out for different cases with different laying configuration, conductor size, resistivity, and the number of armour wires. The calculated results for trefoil and

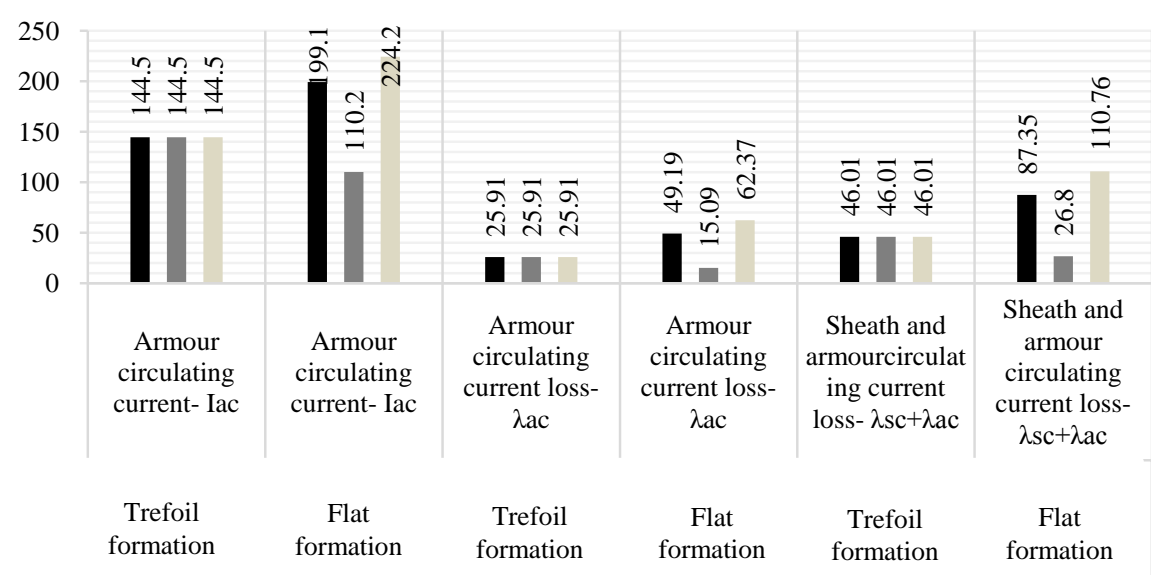

Figure 11. Armour circulating current loss for trefoil and flat arrangement.

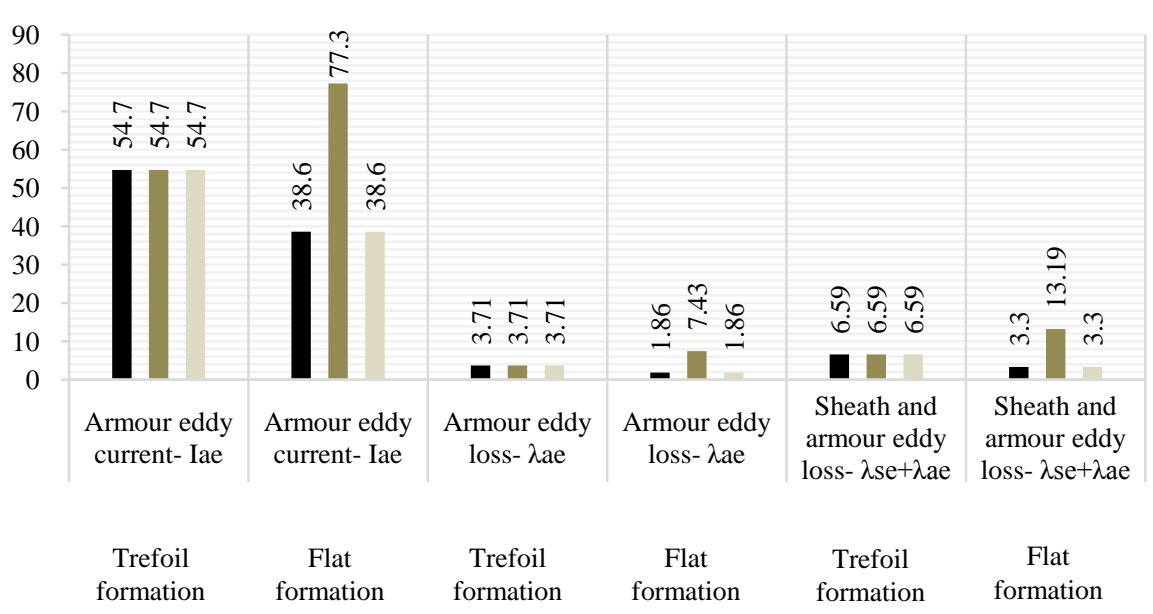

Figure 12. Armour eddy current loss for trefoil and flat arrangement. 
flat configuration also showed that circulating current loss in trefoil configuration is equal in all three phases, but for flat configuration, it is minimum in the middle phase and maximum in the cable which has the lagging phase to the middle cable as illustrated in Figure 13.

To calculate the sheath and armour circulating current loss of a single-core cable with trefoil arrangement, $I_{C S 1}, I_{C S 2}, I_{C S 3}$ as phase 1,2 , and 3 sheath and armour circulating currents are considered equalas in Equation (22) stated in [27].

$$
\left|I_{C S 1}\right|=\left|I_{C S 2}\right|=\left|I_{C S 3}\right|=|I| \frac{\omega M}{\sqrt{R_{S}^{2}+\omega^{2} M^{2}}}
$$

But for flat arrangement, sheath and armour circulating current loss varies with the cables as shown in (23)-(27) from [27]:

$$
\begin{gathered}
\left|I_{C S 1}\right|=|I| \sqrt{\frac{Q^{2}}{4\left(R_{S}^{2}+Q^{2}\right)}+\frac{3 P^{2}}{4\left(R_{S}^{2}+P^{2}\right)}}+\frac{\sqrt{3} P Q R_{S}(Q-P)}{2\left(R_{S}^{2}+Q^{2}\right)\left(R_{S}^{2}+P^{2}\right)} \\
\left|I_{C S 2}\right|=|I| \frac{Q}{\sqrt{R_{S}^{2}+Q^{2}}} \\
\left|I_{C S 3}\right|=|I| \sqrt{\frac{Q^{2}}{4\left(R_{S}^{2}+Q^{2}\right)}+\frac{3 P^{2}}{4\left(R_{S}^{2}+P^{2}\right)}}-\frac{\sqrt{3} P Q R_{S}(Q-P)}{2\left(R_{S}^{2}+Q^{2}\right)\left(R_{S}^{2}+P^{2}\right)} \\
P=X+X_{m} \\
Q=X-\frac{X_{m}}{3}
\end{gathered}
$$

where $I=$ The line current in A.

$R_{s}=$ Resistance of sheath and armour per unit length, at its maximum operating temperature $\Omega \cdot \mathrm{m}^{-1}$.

$\omega=$ Angular frequency in $\mathrm{rad} \cdot \mathrm{s}^{-1}$.

$R=$ Resistance of core conductor per unit length, at its maximum operating temperature $\Omega \cdot \mathrm{m}^{-1}$.

$M=$ Mutual inductance between core, sheath, and armour in $\mathrm{H} \cdot \mathrm{m}^{-1}$.

$X=$ Reactance per unit length of sheath and armour $(\omega M)$ in $\Omega \cdot \mathrm{m}^{-1}$.

And

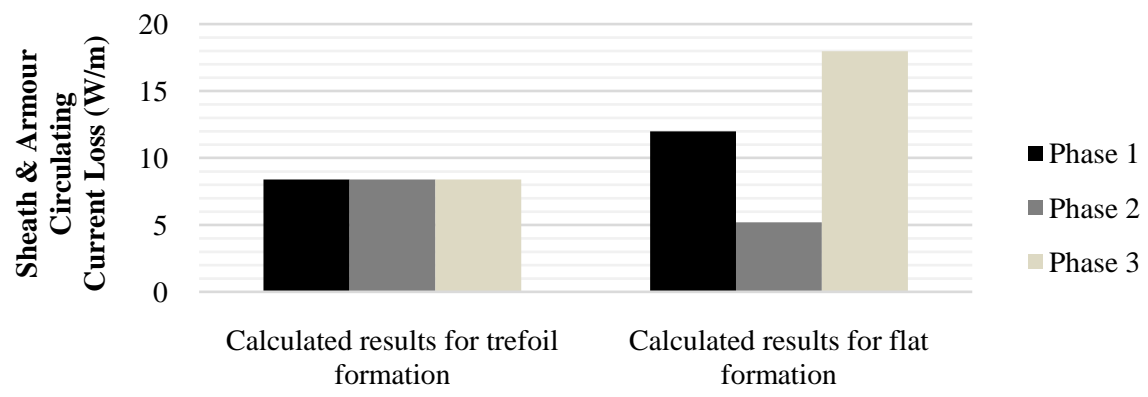

Figure 13. Variation of sheath and armour circulating current loss with trefoil and flat laying formations of cables. 


$$
X_{m}=\omega \times 2 \times 10^{-7} \ln 2
$$

Thus, sheath and armour circulating current loss per unit length of a single core cable $W_{C S}$ in $\mathrm{W} \cdot \mathrm{m}^{-1}$ is calculated as Equation (30):

$$
W_{C S}=I_{C S}^{2} R_{S}
$$

To investigate circulating current variation with different conductor sizes, they applied $315 \mathrm{~A}$ to all different sizes of conductors with trefoil and flat configuration that resulted in increment of the circulating current with greater sizes of the conductor as illustrated in Figure 14 [27].

It's also showed that increasing the resistivity of the cable armour or decreasing the number of armour wires leads to circulating current loss reduction (Figure 15 and Figure 16).

It should be noted that according to IEC 60502-2 and AS/NZS 1429-1 the diameter of the armour wire is not flexible, and nominal diameters of round armour wires shall be not less than the values given in Table 7 [28] [29].

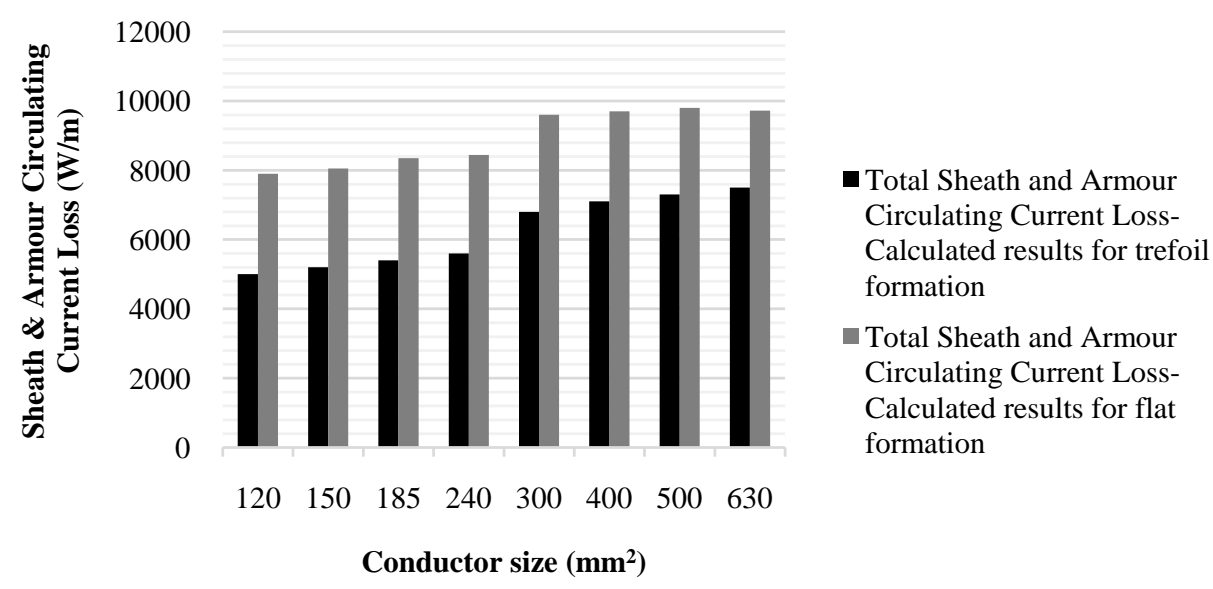

Figure 14. Variation of sheath and armour circulating current loss with conductor size.

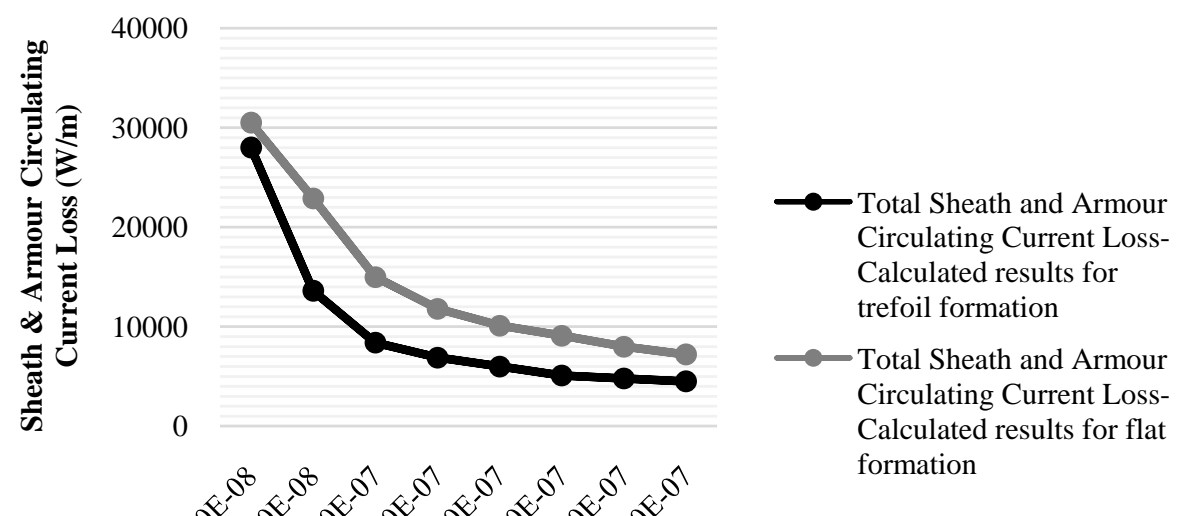

Armour Resistivity $(\Omega \mathrm{m})$

Figure 15. Variation of sheath and armour circulating current loss with the resistivity of the armour. 


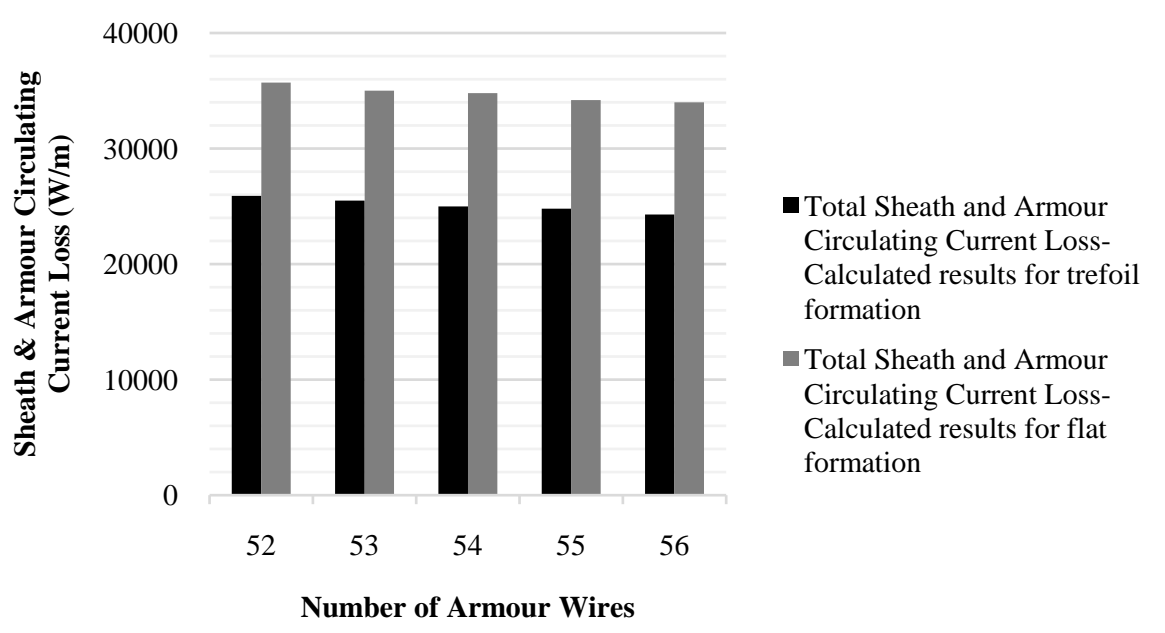

Figure 16. Variation of sheath and armour circulating current loss with quantity of armour wires.

Table 7. Nominal diameter of armour wire.

\begin{tabular}{ccc}
\hline \multirow{2}{*}{$\begin{array}{c}\text { Fictitious diameter under the armour }(\mathrm{mm}) \\
\text { of armour wire }(\mathrm{mm})\end{array}$} & \multicolumn{2}{c}{ Nominal diameter } \\
\cline { 2 - 3 }$<10$ & 0.8 & AS/NZS 1429-1 \\
$>10-\leq 15$ & 1.25 & 1.6 \\
$>15-\leq 25$ & 1.6 & 1.6 \\
$>25-\leq 35$ & 2.0 & 1.6 \\
$>35-\leq 60$ & 2.5 & 2.0 \\
$>60$ & 3.15 & 2.5 \\
\hline
\end{tabular}

\section{Conclusions}

This paper presented a review of literature on the topics of cable armouring, induced voltage and current in the armour of the cables and calculation methods of the armour losses. This research shows that in the case of single-core cables with magnetic armour, extreme losses can occur. In order to reduce the losses of magnetic armours, the use of single-armoured cables with an efficient increase in armour lay by intertwisting the cables, was demonstrated. Although, the flux density in the magnetic armours and the losses were far greater to be practical. As a result, to prevent high losses, further studies on non-magnetic materials have been carried out. It was demonstrated that the use of aluminum rather than steel for armouring has helped to reduce the losses.

This paper also briefly described several techniques that can lead to reduction in circulating current loss, like different laying configurations, increasing the resistivity of the cable armour, or decreasing the number of armour wires. It was concluded that the trefoil formation is preferable to the flat formation, since this configuration distributes the losses evenly over the phases, resulting in a reduction in total sheath and armour circulating current loss. Further investigation of 
the properties of other potential alloys with higher strength and lower losses is required, which will be left to future work.

\section{Conflicts of Interest}

The authors declare no conflicts of interest regarding the publication of this paper.

\section{References}

[1] Liu, C. (2019) Comparison and Selection of Three-Core Cable and Single-Core Cable. IOP Conference Series: Earth and Environmental Science, 300, Article ID: 042047. https://doi.org/10.1088/1755-1315/300/4/042047

[2] Messner, F. (2002) Material Substitution and Path Dependence: Empirical Evidence on the Substitution of Copper for Aluminum. Ecological Economics, 42, 259-271. https://doi.org/10.1016/S0921-8009(02)00052-6

[3] Mys, I. and Schmidt, M. (2006) Laser Micro Welding of Copper and Aluminum. Proceedings of SPIE Laser-Based Micropackaging, Vol. 6107, 610703. https://doi.org/10.1117/12.648376

[4] Passarini, F., Ciacci, L., Nuss, P. and Manfredi, S. (2018) Material Flow Analysis of Aluminium, Copper, and Iron in the EU-28.

[5] Kuchta, F., Coplen, P., Chavarria, G. and Kelley, N. (2015) U.S. Patent No. 9,064,618. U.S. Patent and Trademark Office, Washington DC.

[6] Ristanovic, D., Alwala, S., Bhatia, N. and Hanbali, A. (2015) Medium Voltage Single Core Cable Armor Grounding Issues and Solutions. 2015 IEEE IAS Joint Industrial and Commercial Power Systems/Petroleum and Chemical Industry Conference (ICPSPCIC), Hyderabad, 19-21 November 2015, 251-259. https://doi.org/10.1109/CICPS.2015.7974082

[7] Powers, W.F. (1994) The Basics of Power Cable. IEEE Transactions on Industry Applications, 30, 506-509.

[8] Moore, G.F. (1997) Electric Cables Handbook. 3rd Edition, Wiley-Blackwell, Hoboken, 30 .

[9] Anders, G.J. and Institute of Electrical and Electronics Engineers (2005) Rating of Electric Power Cables in Unfavorable Thermal Environment. Wiley, New York.

[10] Orini, A. (2014) U.S. Patent No. 8,686,290. U.S. Patent and Trademark Office, Washington DC.

[11] Moore, G.F. (1997) Electric Cables Handbook. 3rd Edition, Wiley-Blackwell, Hoboken, 40-41.

[12] Ryan, M. (2011) An Investigation into the Feasibility of Migrating from PILC to XLPE as the Cable Technology of Choice for Medium Voltage Electricitiy Networks in South Africa. Doctoral Dissertation.

[13] (2005) Rating of Electric Power Cables in Unfavorable Thermal Environment. Wiley.Com, 63 .

[14] Mo, N. (1990) Electric Power Distribution Systems Operations.

[15] Rasoulpoor, M., Mirzaie, M. and Mirimani, S.M. (2016) Electrical and Thermal Analysis of Single Conductor Power Cable Considering the Lead Sheath Effect Based on Finite Element Method. Iranian Journal of Electrical and Electronic Engineering, 12, 73-81. 
[16] Maioli, P. and Bechis, M. (2020) U.S. Patent No. 10,839,984. U.S. Patent and Trademark Office, Washington DC.

[17] Standard, I.E.C. (1982) Calculation of the Continuous Current Rating of Cable (100\% Load Factor).

[18] Bosone, L. (1931) Contributo allo studio delle perdite e dell'autoinduzione dei cavi unipolari armati con fili di ferro. L'Elettrotecnica, 18, 2-8.

[19] Whitehead, S. and Hutchings, E.E. (1938) Current Rating of Cables for Transmission and Distribution. Journal of the Institution of Electrical Engineers, 83, 517-557. https://doi.org/10.1049/jiee-1.1938.0170

[20] Lee, J.M., Park, D.J., Jeong, G.Y., Lee, C.H., Kim, J.N., Jeon, S.I., Kaumanns, J., et al. (2016) Measurements and FEA Results of Steel Armour Losses in Three-Core Submarine XLPE Cables. Proc. Cigré.

[21] Palmgren, D., Karlstrand, J. and Henning, G. (2011) Armour Loss in Three-Core Submarine XLPE Cables. International Conference on Insulated Power Cables, Versailles, 19-23 June 2011.

[22] Brockbank, R.A. and Webb, J.K. (1929) Sheath and Armour Losses in Single-Core Cables for Single-Phase and Three-Phase Transmission. Journal of the Institution of Electrical Engineers, 67, 337-358. https://doi.org/10.1049/jiee-1.1929.0031

[23] Harvey, G.M. and Busby, A.H.W. (1925) The Use of Single-Core Armoured Cables for Alternating Currents. Journal of the Institution of Electrical Engineers, 63, 368-378. https://doi.org/10.1049/jiee-1.1925.0041

[24] Cramp, W. (1925) The Use of Single-Core Lead-Covered and Armoured Cables for Alternating Currents. Journal of the Institution of Electrical Engineers, 63, 379-383. https://doi.org/10.1049/jiee-1.1925.0042

[25] Barrett, J.S. and Anders, G.J. (1997) Circulating Current and Hysteresis Losses in Screens, Sheaths and Armour of Electric Power Cables-Mathematical Models and Comparison with IEC Standard 287. IEE Proceedings-Science, Measurement and Technology, 144, 101-110. https://doi.org/10.1049/ip-smt:19971162

[26] Gouda, O.E. and Farag, A.A.E. (2012) Factors Affecting the Sheath Losses in Single-Core Underground Power Cables with Two-Points Bonding Method. International Journal of Electrical \& Computer Engineering, 2, 7-16. https://doi.org/10.11591/ijece.v2i1.115

[27] Ariyasinghe, A., Warnakulasuriya, C., Kumara, S. and Fernando, M. (2019) Optimizing Medium Voltage Underground Distribution Network with Minimized Sheath and Armor Losses. 2019 14th Conference on Industrial and Information Systems (ICIIS), Kandy, 18-20 December 2019, 119-124. https://doi.org/10.1109/ICIIS47346.2019.9063265

[28] Standard, IEC 60502 (2005) Part 2: Cables for Rated Voltages from $6 \mathrm{kV}(\mathrm{Um}=7,2$ $\mathrm{kV})$ up to $30 \mathrm{kV}(\mathrm{Um}=36 \mathrm{kV})$.

[29] Standard AS/NZS1429.1 (2006) (R2017), Electric Cables-Polymeric Insulated-For Working. 